\title{
Studies on PEBAX/organoclay nanocomposites by melt- intercalation process: Effect of organoclay surface
}

\author{
Somayeh Mohamadi, Naser Sharifi Sanjani \\ "School of Chemistry, University College of Science, University of Tehran, P. O. Box: \\ 14155-6455, Tehran, Iran; fax: +98 21 66405141; e-mail: smohamadi@khayam. \\ ut.ac.ir
}

(Received: 10 June, 2008; published: 16 November, 2009)

\begin{abstract}
In this study, the polyetherblock amide (PEBAX) ${ }^{\circledR}$ nanocomposites with $2.5 \%$ and 5 wt. \% organoclay, based on Cloisite 30B (montmorillonite intercalated with dimethyl, 2-ethyl hexyl hydrogenated tallow alkyl ammonium cation), were prepared by the melt-intercalation process. The structural properties, thermal behaviors and the mechanical properties were characterized using the X-ray diffraction (XRD), Fourier transform infrared spectroscopy (FT-IR), melt flow index (MFI), differential scanning calorimetry (DSC), thermogravimetry analyses (TGA), transition electron microscopy (TEM), scanning electron microscopy (SEM) and the tensile test. The XRD analysis indicated the formation of intercalated PEBAX nanocomposites. The TGA results revealed that the addition of $2.5 \mathrm{wt} . \%$ nanoclay improved the thermal properties, while the nanocomposite with $5 \mathrm{wt} . \%$ nanoclay did not enhance the thermal stability. The DSC analysis indicated that, in the case of PEBAX with 2.5 wt.\% organoclay, each peak was related to the fusion of the crystalline fraction of the poly ether and poly amide affected blocks. On the contrary, regarding the PEBAX with 5 wt.\% nanoclay, only the peak related to polyamide was changed. Interestingly, the tensile modulus increased with the incorporation of $2.5 \mathrm{wt} . \%$ clay, but it decreased in PEBA 5. The elongation at break reduced with the incorporation of the clay, attaining a minimum value at the clay concentration of $2.5 \mathrm{wt} . \%$, and followed by an increase at the clay concentration of 5 wt.\%.
\end{abstract}

\section{Introduction}

The polymer/layered silicate nanocomposites (PLSNs) have attracted strong interest in recent materials research because of the high surface area and surface reactivity of layered silicate [1-3]. PLSNs are synthesized by swelling the inter layer regions of the layered nanostructure by the polymer or a corresponding monomer [4].

The addition of only $2-5$ wt.\% clay fillers can double the tensile strength and modulus, reduce the gas permeability and improve the thermal properties, such as the coefficient of the linear thermal expansion and the heat distortion temperature [5- 9].

Thermodynamics play a significant role in the determinination of the PLSNs formation. The overall length and density of the surfactants in the galleries, the length of the polymer chains and the enthalpic (polymer/silicate and the polymer/surfactant) interactions determine the phase behavior of the polymer/clay systems [10].

Two idealized polymer-layered silicate structures are conventionally discussed; (i) the exfoliated structure and (ii) the intercalated structure. The fully exfoliated PLSNs consist of individual nanometer-thick silicate layers, randomly suspended in a polymer matrix. In this way, an interfacial area of a mass ratio, approaching 700 
$\mathrm{m} 2 / \mathrm{g}$, is obtained. In contrast, the intercalated structures result from polymer penetration and expansion of the original silicate crystallites to a thermodynamically defined equilibrium spacing [11].

The thermodynamic aspect of the polymer intercalation in organically modified layered silicates has been recently studied [5]. It was proposed that the entropy loss of the polymer chains upon confinement between sheets was compensated by the increased conformation of the tethered surfactant chains as the layers separated, resulting in a stable intercalated structure. For exfoliation to occur, additional enthalpic gains were necessary to drive the system to a stable dispersion.

As mentioned above about conformation of the tethered surfactant chains, on the basis of clay CEC (cation exchange capacity) and carbon atom chain length, the alkyl ammonium (confined between two clay layers) adopts a monolayer, bilayer or trilayer structure $[12,5]$.

Despite the high number of the PLSNs studies, there are several questions that have not been answered yet: (a) exactly which polymer groups interact with which chemical groups of the clay surface, (b) the polymer conformation and (c) the amount of polymer absorbed under different physical conditions [13].

The influence of an interface is more complicated for an ordered block copolymer, which alters the degree of ordering and packing perfection and the structure as well as the organization.

The Poly Ether Block Amide (PEBAX) $®$ resin is a thermoplastic elastomer combining linear chains of rigid polyamide segments inter spaced with flexible polyether segments. This crystalline/amorphous structure creates a blend of thermoplastic and rubber properties. Currently, the main commercial application range can be defined from sporting goods (shoe soles), industrial equipment (covery of bells) in addition to fundamental films (breathable clothing, drying films) and other materials [14, 15].

In this paper, the organophilically treated montmorillonite (OMMT) and PEBAX® were intercalated by the melt-intercalation process. An attempt is described to use a block copolymer, containing polyethylene oxide and polyamide, which can behave separately when reside at the silicate interface. Also, the effect of the silicate surface and its organic groups on each block was examined.

\section{Results and discussion}

\section{$X$-ray diffraction $(X R D)$}

$X R D$ is the most powerful and reliable technique to study the nanoclay dispersion inside the polymer matrix through Bragg's relation: $\lambda=2 \mathrm{~d} \sin \theta$. Fig. 1 depicts the XRD patterns of the nanocomposites, based on the two organoclay concentrations and neat organoclay. The XRD pattern of PEBA 2.5 illustrates no strong diffraction peak, while the basal spacing of organoclay $d_{(001)}$ is $1.18 \mathrm{~nm}$ corresponding to $2 \theta=4.56^{\circ}$ (Fig. 1 (B)). This indicated that exfoliated morphology had occurred and the polymer chains could enter the interlayer spacing of organoclay and separate them.

But in the case of PEBA 5, two small peaks at the wavelength of $6.025 \mathrm{~nm}(2 \theta=$ $1.46)$ and $3.72 \mathrm{~nm}(2 \theta=2.37)$ can be observed. This showed that some of the clay networks could not exfoliate to the silicate sheets and the intercalation has occurred that coexists with exfoliated morphology. Since the extrusion conditions for both nanocomposites are equal, the difference in the formed nanostructure was assigned 
to the difference in the clay content. Actually, from these results, it can be stated that the tendency of the PEBAX chains to penetrate into the galleries of the silicate layers decreased with the organoclay content, In other words, with increasing the clay content, complete exfoliation of such high aspect ratio silicate layers got more and more hindered. Actually, due to the high interaction between PEBAX chains with organoclay surface, the mobility of chains is restricted. Therefore the exfoliation structure and the content of individual layered silicate will be dominant in PEBA 2.5.

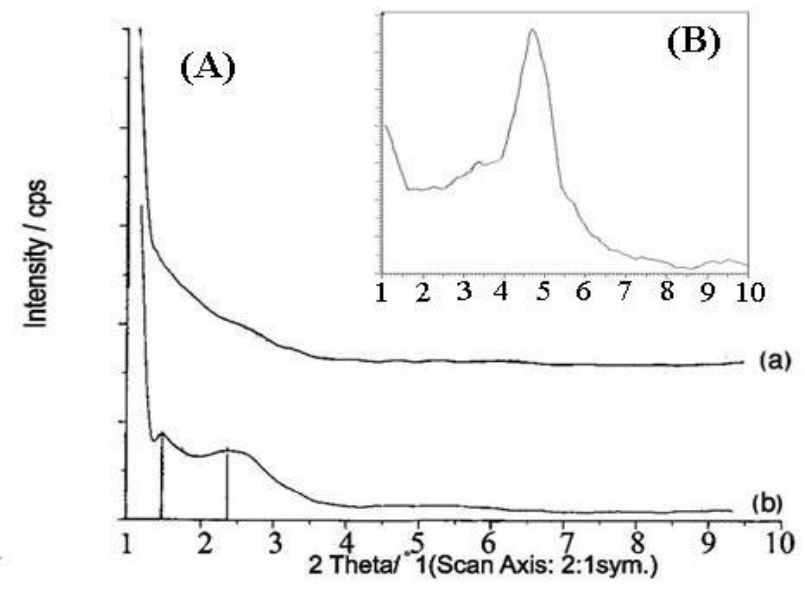

Fig. 1. X-ray diffraction of (A) the PEBA 2.5 (a) and PEBA 5 (b) and (B) cloiste 30B.

Further characterization of PEBA5 nanocomposite by TEM is shown in Fig. 2. The dark lines in the TEM images are silicate layers. It is revealed that intercalated morphology is coexisting with exfoliated state which is in good agreement with XRD results.

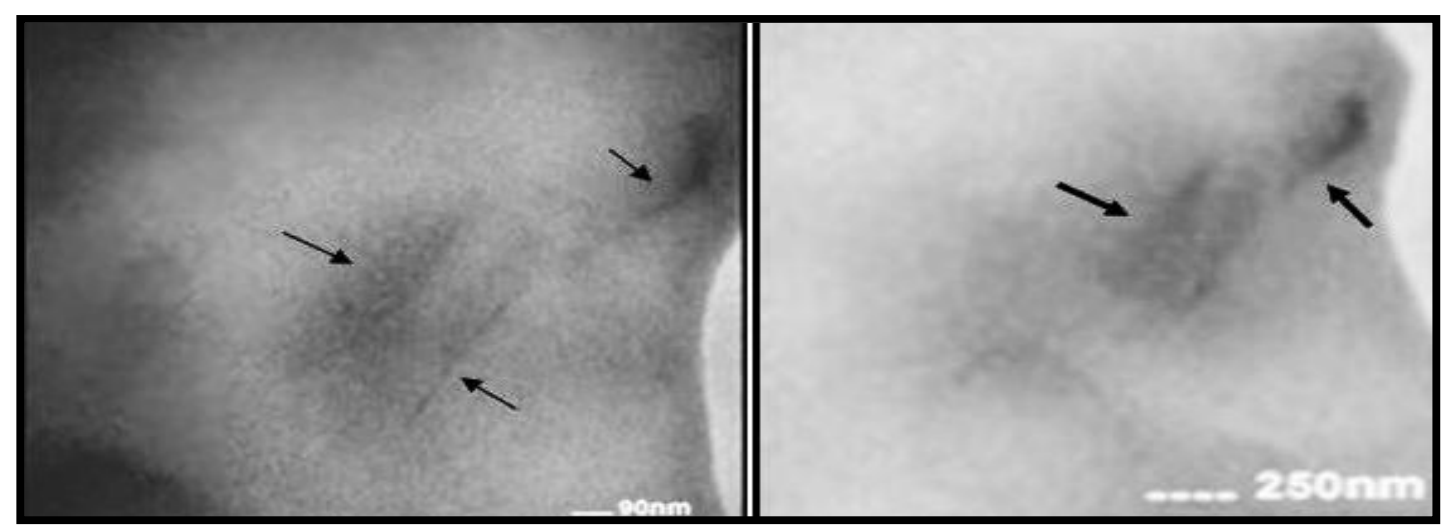

Fig. 2. TEM photographs of PEBA5 nanocomposite with different scale bar.

\section{FT-IR spectroscopy}

The polymer/clay nanocomposite sample was also characterized by the FT-IR spectroscopy. The FT-IR spectroscopy provides important information regarding the difference between the polymer and the polymer hybrid.

The FT-IR spectra of the PEBAX/organoclay nanocomposite and the FT-IR spectra of the pure PEBAX and Cloisite 30B are depicted in Fig. 3. 
The pure PEBAX illustrates the bands of the asymmetric and symmetric $-\mathrm{CH}_{2}$ stretching at 2919.29 and $2850 \mathrm{~cm}^{-1}$. The band of $3273 \mathrm{~cm}^{-1}$ was related to the $\mathrm{N}-\mathrm{H}$ band stretching. The peaks at the wavelength of 1734,1637 and $1106.2 \mathrm{~cm}^{-1}$ were assigned to the stretching of the esteric (the carboxyl groups of the carboxylterminated $\mathrm{PA}_{12}$ which combine with hydroxyl groups of PEO chains) and amidic carbonyl groups and the asymmetric stretching of the etheric $\mathrm{C}-\mathrm{O}-\mathrm{C}$ band, respectively. As it can be observed in the Cloisite 30B FT-IR spectra, the absorption band at $1000-1100 \mathrm{~cm}^{-1}$ corresponded to the Si-O-Si stretching vibrations, while a new peak appeared in the nanocomposite at the wavelength of $1080 \mathrm{~cm}^{-1}$, related to this absorption band. In the region of $800-900$, we note peaks at 812 and $838 \mathrm{~cm}^{-1}$ getting stronger with the addition of organic clay, which is assigned to the $\mathrm{CH}_{2}$ rocking of vibrations of methylene groups in the gauche conformation required for the helical conformation. So, it is believed that the ether oxygen of the PEO block in the PEBAX could complex with some of the modifier cations. As a consequence, addition of organoclay caused the PEO block to form spring configuration as little as possible $[16,17,34]$. In other words, the crystalline state of PEO is in the helical structure and the gauche conformation of the- $\mathrm{CH} 2 \mathrm{CH} 2-$ is requires for a helical PEO conformation $[34,35,36]$. As a result, it could be said the addition of organoclay in PEBA2.5 has increased the crystalline form of PEO which is in agreement with DSC results (See Fig.6 (c)).

\section{Thermal gravimetric properties}

The macroscopic properties of nanocomposites investigated in our study include thermal degradation temperature, thermal transition temperatures, melt flow index and mechanical behavior. Thermogravimetric analysis (TGA) was performed on the materials to obtain information on their degradation. In Fig. 4 the TGA curves of PEBAX and the PEBAX/30B nanocomposites with 2.5 and 5 wt.\% of organoclay (A) and cloisite 30B (B) are compared. As can be seen in Fig.4 (B) the initial degradation of the neat organoclay is $180^{\circ} \mathrm{C}$.

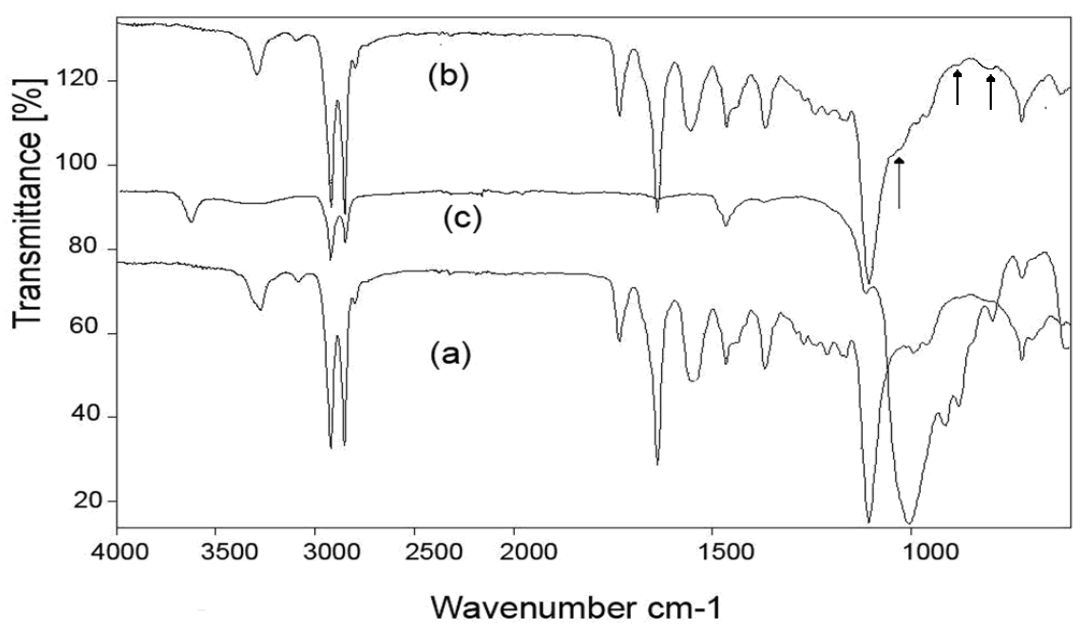

Fig. 3. FTIR spectra of the PEBA 0 (a), PEBA 2.5 (b) and Cloisite 30B (c).

The decomposition process of neat organoclay exhibits two parts, in which the second part is larger than the first in the range of about $310-460{ }^{\circ} \mathrm{C}$. Hu and coworkers found the first step of degradation gave mainly long carbon chains with 
chloro or amine groups [18]. In our work, this can be attributed to the two phenomena:

(i) The generation of amine groups results from Hoffman elimination of $\beta$ hydrogen in 2- hydroxyethyl groups of ammonium salts.

(ii) The degradation of organic compounds which are outside space of the silicate layers which could take place at lower temperature.

However, the initial degradation of two nanocomposites was lower than that of the neat PEBAX, associated with the degradation of the organic groups, which were used as modifiers of the silicate layers.

The temperature at which $50 \%$ of the weight loss increased with the $2.5 \%$ organoclay addition (the temperature was $443.75^{\circ} \mathrm{C}$, compared with $425^{\circ} \mathrm{C}$ for the neat PEBAX), while increasing the organoclay content to $5 \mathrm{wt} \%$, did not improve the thermal stability of the nanocomposite significantly. The increase in the thermal stability of the nanocomposite at up to $50 \%$ weight loss is mainly due to formation of char which hinders the out-diffusion of the volatile decomposition products, Gilman et al reported the formed char layer acted as an insulator and mass transport barrier and therefore reduces the mass loss rate [19, 32], while, when much more exfoliated clay is formed, char formation becomes more easy and efficient [20].

On the other hand, the barrier effect of the clay layer structure due to the restriction of the chain mobility comes from the strong interaction between the organoclay and the polymer macromolecules, and "Tortuous" path of the diffusing molecule is another reason of the thermal stability $[5,21,22]$.

In addition, as reported by $\mathrm{H}$. Zhou et al clay as stacks and agglomerates can result in increasing the thermal conductivity of layered silicate, which has been observed in the high loading of organoclay. Actually, the influence of the size effect and interface effect becomes very small, due to large size of clay. So the thermal convection from the layered silicate to the polymer chains takes place more easily [29]. Therefore, in the PEBAX/ organoclay hybrids, the hybrids possessed a higher thermal stability when OMMT was well-dispersed. The TGA curves indicated that the PEBA 2.5 nanoclay dispersion was higher than PEBA 5.

Finally, as it is displayed in the d-TGA thermogram of the nanocomposites in Fig.5 (A), two distinct degradation steps can be seen. The first step was assigned to the degradation of the organic groups that were employed as modifiers.

It is apparent from these thermograms of the composites that the intensity of this degradation step was stronger in the PEBA 5 nanocomposites. During the time the surfactant decomposition is proceeding according to the Hofmann elimination mechanism, the ammonium cation loses an olefin and an amine and leaves an acid proton on the surface of the MMT. These amine groups and acid site probably result in undesired side reactions [20,23]. These side reactions between the products and the polymer matrix could lead to the matrix degradation. With the increase in the organoclay content, the surfactant content increased and accelerated the matrix degradation which can be seen at the second step of degradation in the PEBA5. 


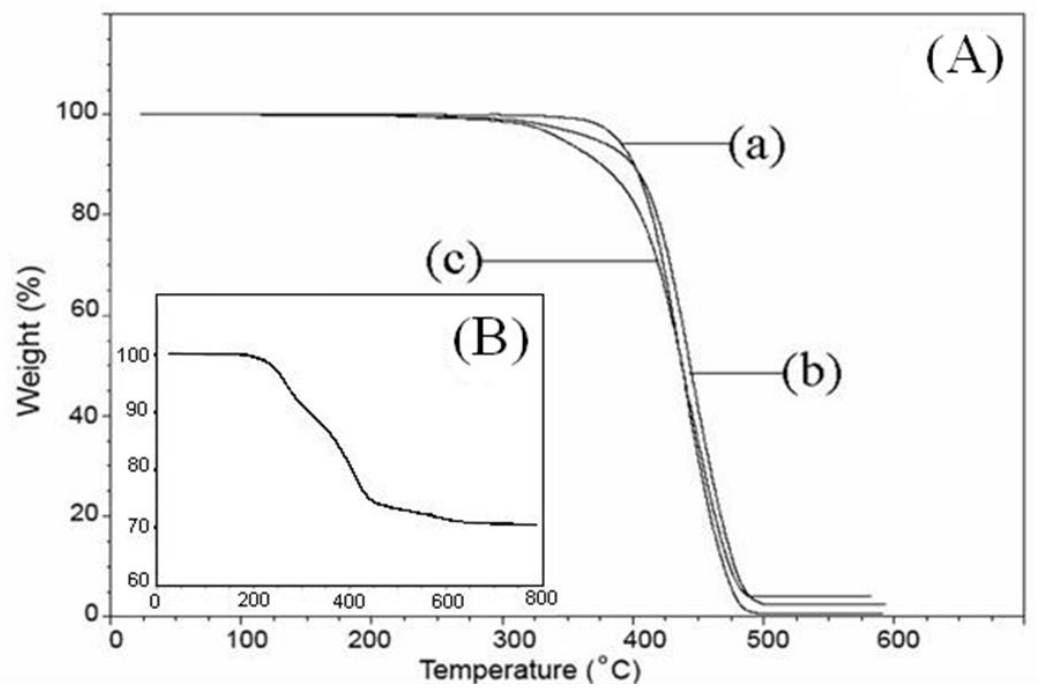

Fig. 4. Temperature dependence of the weight loss for PEBA 0 (a), PEBA 2.5 (b) and PEBA 5 (c).

\section{DSC studies}

DSC studies were taken for the PEBAX resin with organoclay loading. Fig. 6 exhibits these DSC curves for the PEBAX/30B nanocomposites. For PEBA 0 , two endothermic peaks are evident, whose minima occur approximately at $38^{\circ} \mathrm{C}$ and 148 ${ }^{\circ} \mathrm{C}$. These endothermic peaks could be attributed to the crystalline fraction fusion of the poly(ethylene oxide) (PEO) and poly amide 12 (PA12) blocks, respectively. The PEO amorphous phase clearly presents a glass transition temperature around $1^{\circ} \mathrm{C}$ (Fig. 6).

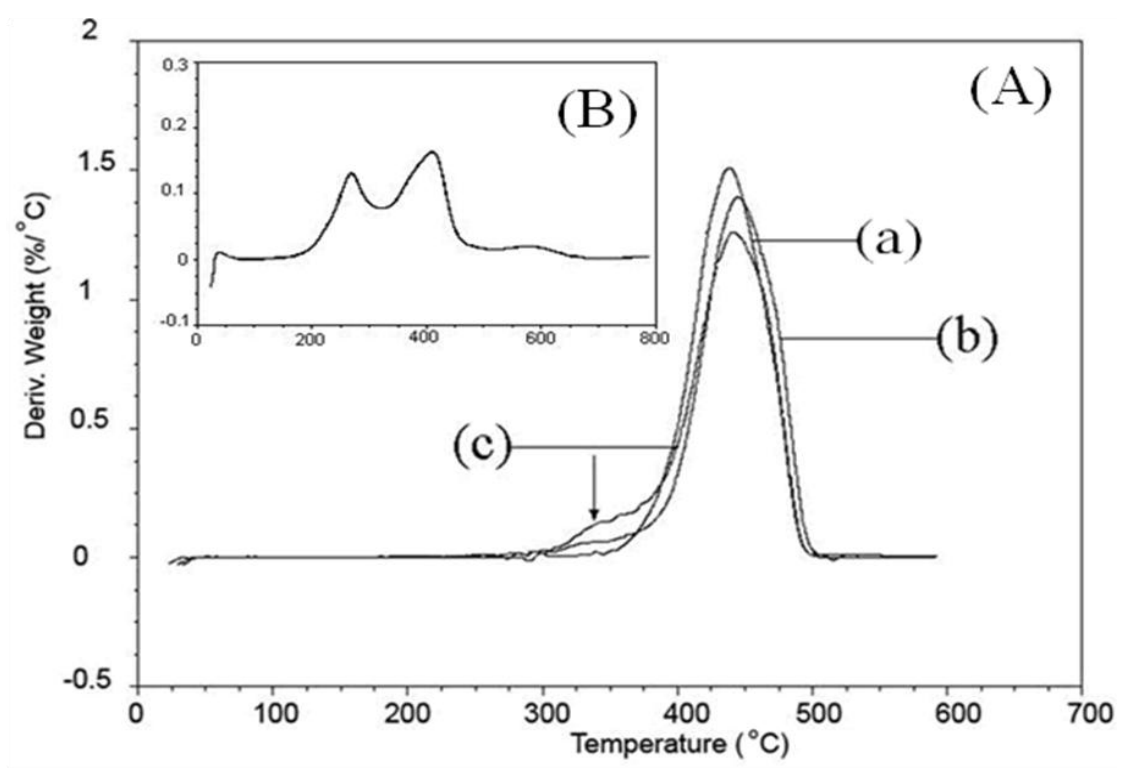

Fig. 5. d-TGA curves of PEBA 0 (a), PABA 2.5 (b), PEBA 5 (c) (A) and cloisite 30B.

However, the glass transition temperature $\left(T_{g}\right)$ in the case of PEBA 5 has diminished. As mentioned in the FT-IR studies, it can be suggested that some of the ether oxygen of the PEO block in the PEBAX could complex with some of the modifier 
cations, positioned between the silicate clay layers. The long carbon chains of ammonium salt were squeezed by the PEO block and increased the free volume, creating a plasticizing effect $[24,25]$. Of course, the combination of the two reversed effects (the mobility limitation of the chains in the presence of the montmorillonite surface and the plastic effect of the ammonium salts, squeezed by the PEO block) caused the shifting of $\mathrm{T}_{\mathrm{g}}$ to be insignificant. In the case of the intercalated PEBA 5 nanocomposite in which the polymer chains are sandwiched between OMMT sheets and are overlapped with modifier groups, this plasticizing effect has become important and $\mathrm{T}_{\mathrm{g}}$ diminishes. While, in PEBA 2.5, since the amount of the individual layered silicate is dominant, the interfacial area between polymer chains and silicate surface is larger and that is why the $T_{g}$ has increased.

The organoclay addition affected the peak of the PA 12 blocks, as well. As it is depicted in Fig. 6, significant difference can be observed in the endothermic peak of the PA 12 blocks.

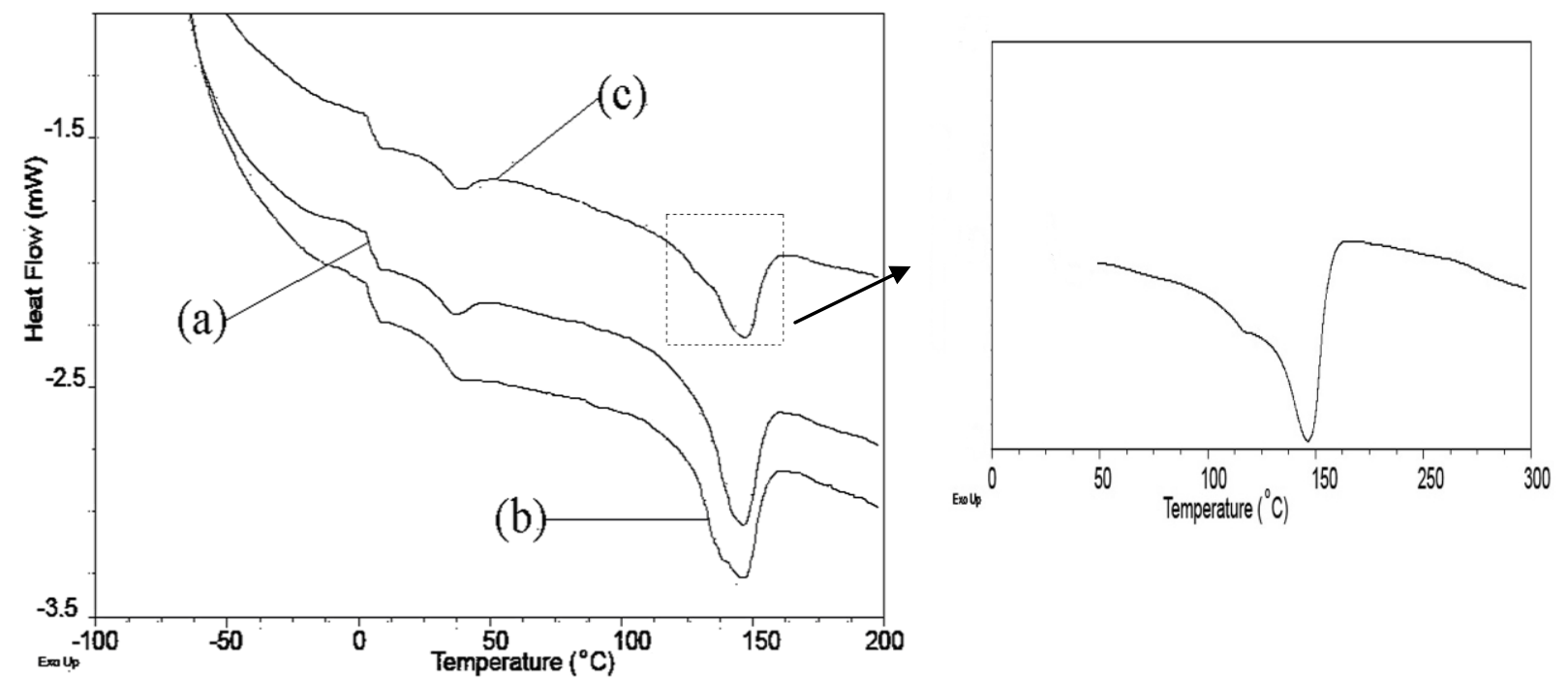

Fig. 6. DSC thermogram for PEBA 0(a), PEBA 2.5(b) and PEBA 5(c).

From these curves, the small and broad peaks can be noticed near the major peak at $116{ }^{\circ} \mathrm{C}$ in PEBA 5. This peak increased in the case of PEBAX/30B nanocomposite with 2.5 wt. \% of the nanoclay. Also, the peak corresponding to the PEO blocks was affected in PEBA 2.5, becoming broader, while this peak in PEBA 5 did not change significantly. These results indicated that in PEBA 2.5 tendency of PEBAX chains to enter the galleries of the silicate layers was higher than that in PEBA 5. SO the interfacial area between polymer chains and layered silicate is higher in exfoliated PEBA 2.5 and each block could reside near the silicate surface, probably altering the structure and the organization of the block copolymer chains. This conclusion can be seen in the SEM images in Fig. 6 better. It can be observed that the surface of the block copolymer presents a different aspect when organoclay was used. It seems that the morphology of crystalline domains of PEBAX has altered and the size of the crystallites has become smaller. 


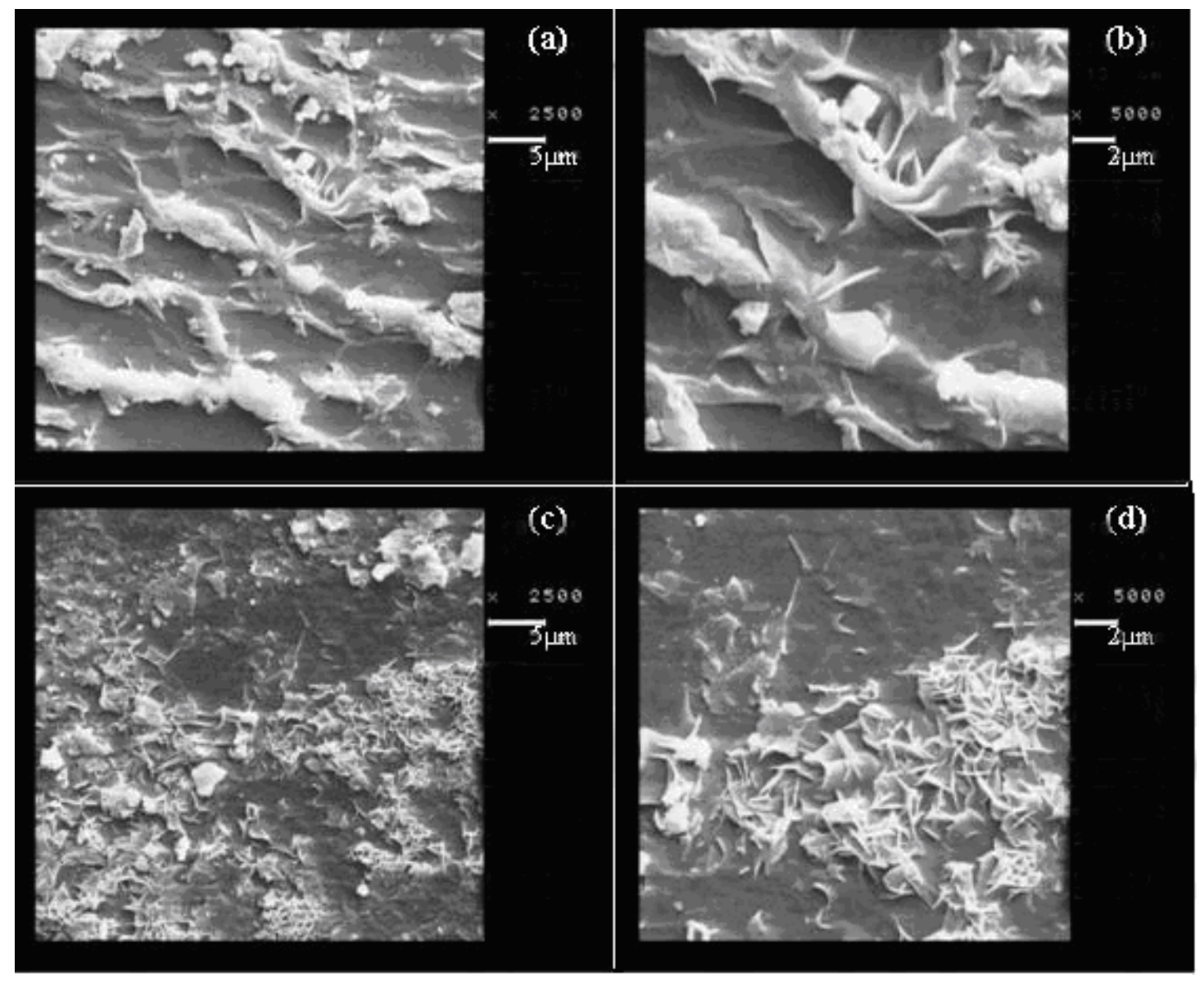

Fig. 7. Morphology of the block copolymer in the PEBAO (a, b) and PEBA2.5 (c, d).

\section{MFI Test}

The melt flow index (MFI) is a widely used rheological polymer property and, occasionally, the standalone rheological information used in the industry [26].

The presence of the interactions between the polymer chains and the silicate surface may affect the mobility and the rheological properties of the polymer chains. Therefore, the nanoclay addition should decrease the polymer MFI in polar polymers. However, in the case of IPP/organoclay nanocomposites, as reported by K. Wang, et al due to the lack of these interactions between the polymer chains and silicate surface, the MFI variations with OMMT content is quite different, so that the increase in the melt fluidity observed at low content of OMMT (> 5 wt.\%) [27].

Tab. 1. MFI test for PEBA 0, PEBA 2.5 and PEBA 5.

\begin{tabular}{cc}
\hline $\begin{array}{c}\text { Content of } \\
\text { clay }(\%)\end{array}$ & $\begin{array}{c}\mathrm{MFI}(\mathrm{g} / 10 \mathrm{~min}) \\
190^{0} \mathrm{C}, 2160 \mathrm{~g}\end{array}$ \\
\hline 0 & 15.58 \\
2.5 & 12.50 \\
5 & 13.77 \\
\hline
\end{tabular}

As it is summarized in Table 1, the polymer MFI reduced to lower degree in the PEBA 2.5 nanocomposite than in PEBA 5. This result revealed that the penetration of the polymer chains into the interlayer space of the organoclay in PEBA 2.5 was 
greater compared with that in PEBA 5. Consequently, the interaction between the polymer chains and the silicate layer should be stronger in PEBA 2.5 rather than in PEBA 5.

\section{Mechanical properties}

The tensile test was conducted in order to obtain an idea of the behavior of the two blocks of the poly(ethylene oxide-co-amide 12), when they reside near the organoclay surface.

The tensile modulus together with the elongation at break, determined from the stress-strain plots, as a function of the clay content, are presented in Figs. 8a and b respectively.
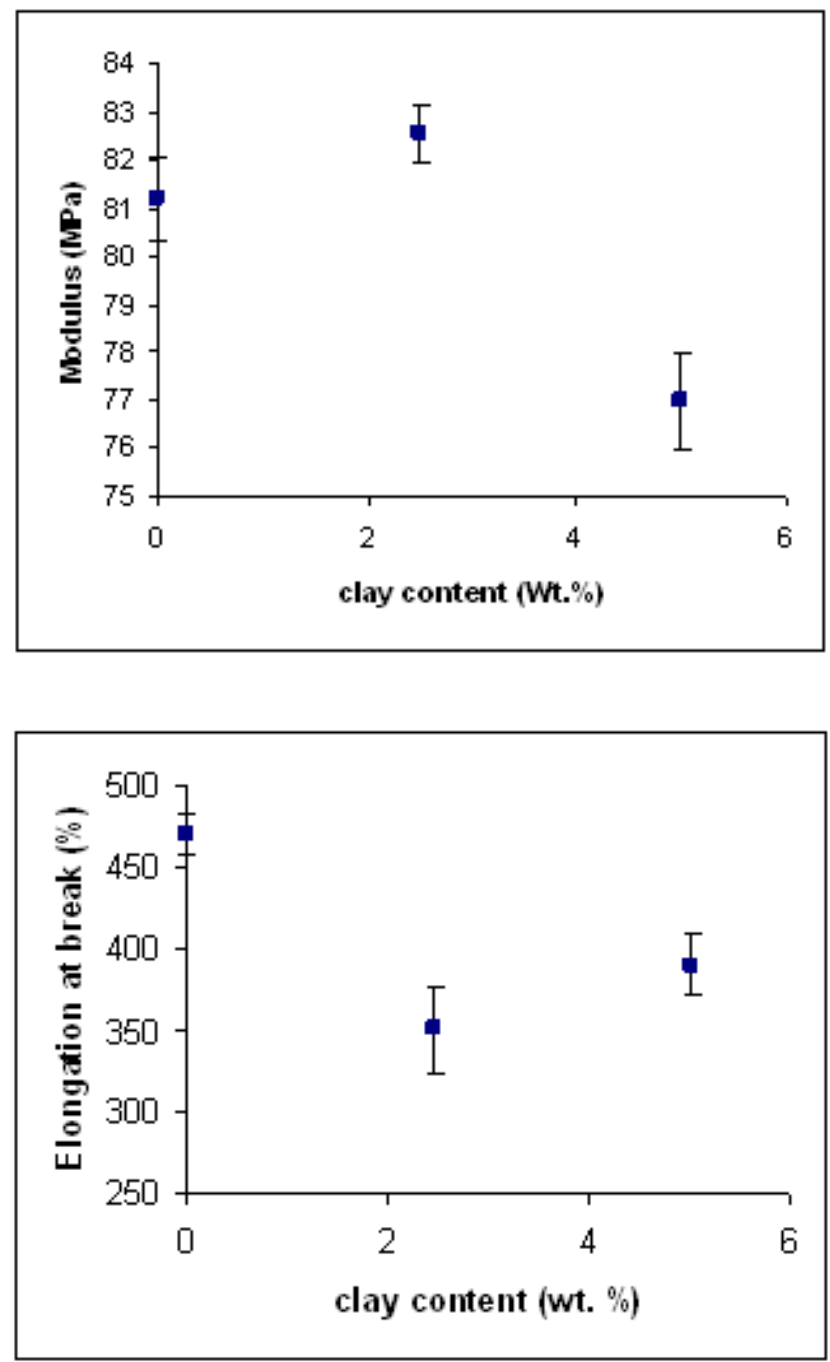

Fig. 8. Effect of the clay loading on (a) the tensile modulus, (b) the elongation at break.

Fig. 8a interestingly displays that the tensile modulus increased with the incorporation of $2.5 \mathrm{wt} . \%$ clay, but it decreased in PEBA 5. In a polar polymer-organoclay systems, where the molecular chains with polar groups would interact with the surfaces of clay platelets can be regarded as the physical crosslink points 28 . These physical cross- 
links cause an increase in the modulus in PEBA 2.5. But in PEBA 5, as it has been reported in Section 3.4 for the DSC curve of PEBA 5, some of the ammonium salt which was squeezed by the PEO block could behave as plasticizer, making PEBA 5 softer.

From Fig $8 \mathrm{~b}$, it is obvious that the elongation at break decreases with the clay incorporation attaining a minimum value at the clay concentration of $2.5 \mathrm{wt} . \%$, followed by an increase at the clay concentration of $5 \mathrm{wt} . \%$. It can be suggested that the clay incorporation has influenced the crystallinity of the PA and PEO blocks, acting as nucleation centers 17, 29.

Actually, the PEBAX rubber elasticity behavior is associated with the structure of the PA and PEO blocks. Subsequently, the crystallinity increase of each block may alter the PEBAX rubber elasticity behavior by decreasing it. On the other hand the physical cross-links as a consequence of silictate sheets can decrease the elongation at breaks of the nanocomposites. Nonetheless, all these results indicated that the uniform dispersion of the silicate layers for PEBA 2.5 and that the existence of the individual sheets has caused different macroscopic properties from PEBA 5.

\section{Conclusions}

The study revealed that the nanostructure and the resulting thermal, mechanical and crystalline behavior of the melt compounded PEBAX/clay nanocomposites were highly sensitive to the extent of the clay dispersion.

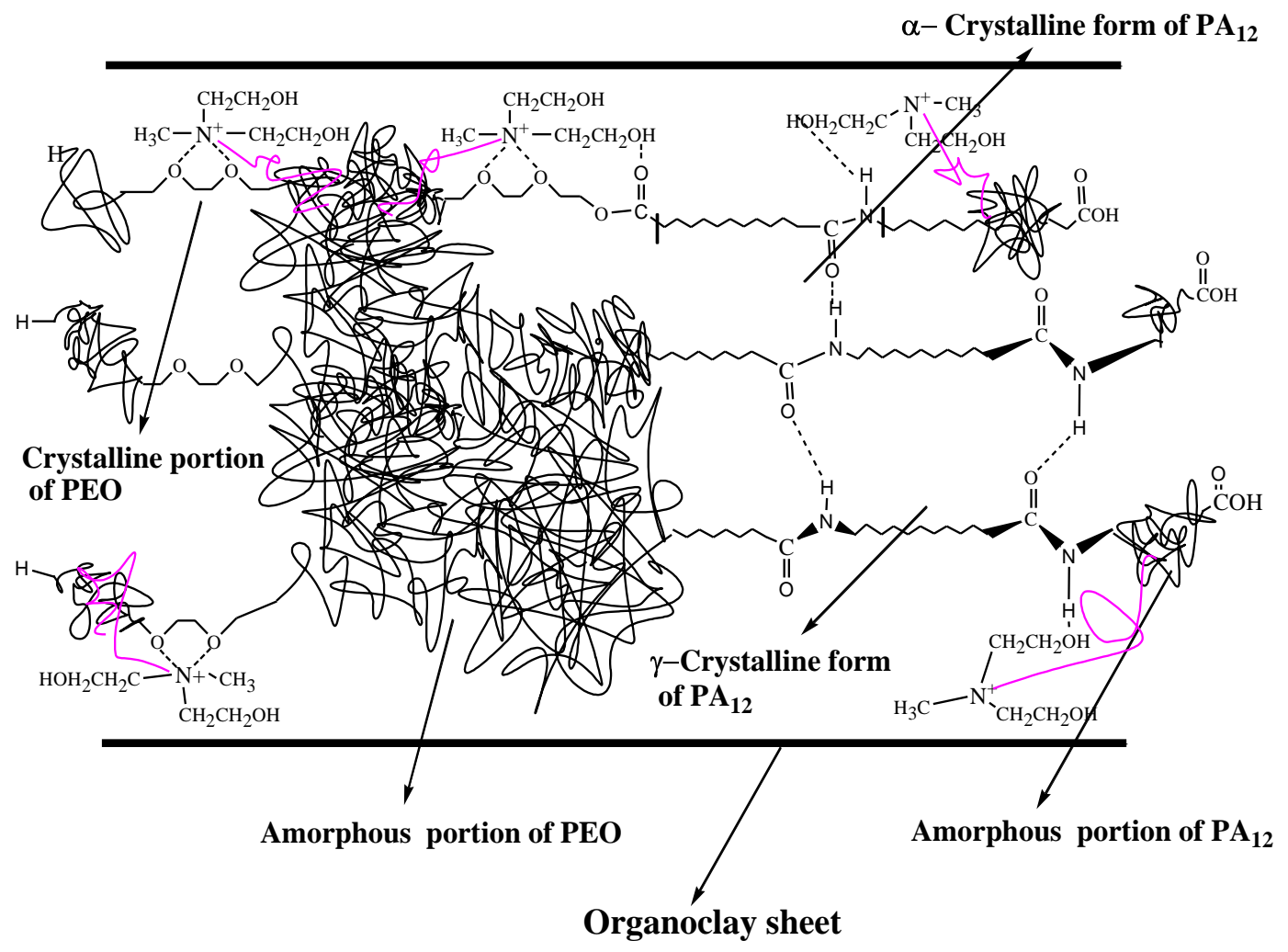

Fig. 9a. Schematic drawing showing the intercalation of PEBAX chains into the galleries of organoclay and combination of two reversed effect of montmorillonite surface and plasticizer effect of modifier groups in which the latter has become more intense. 


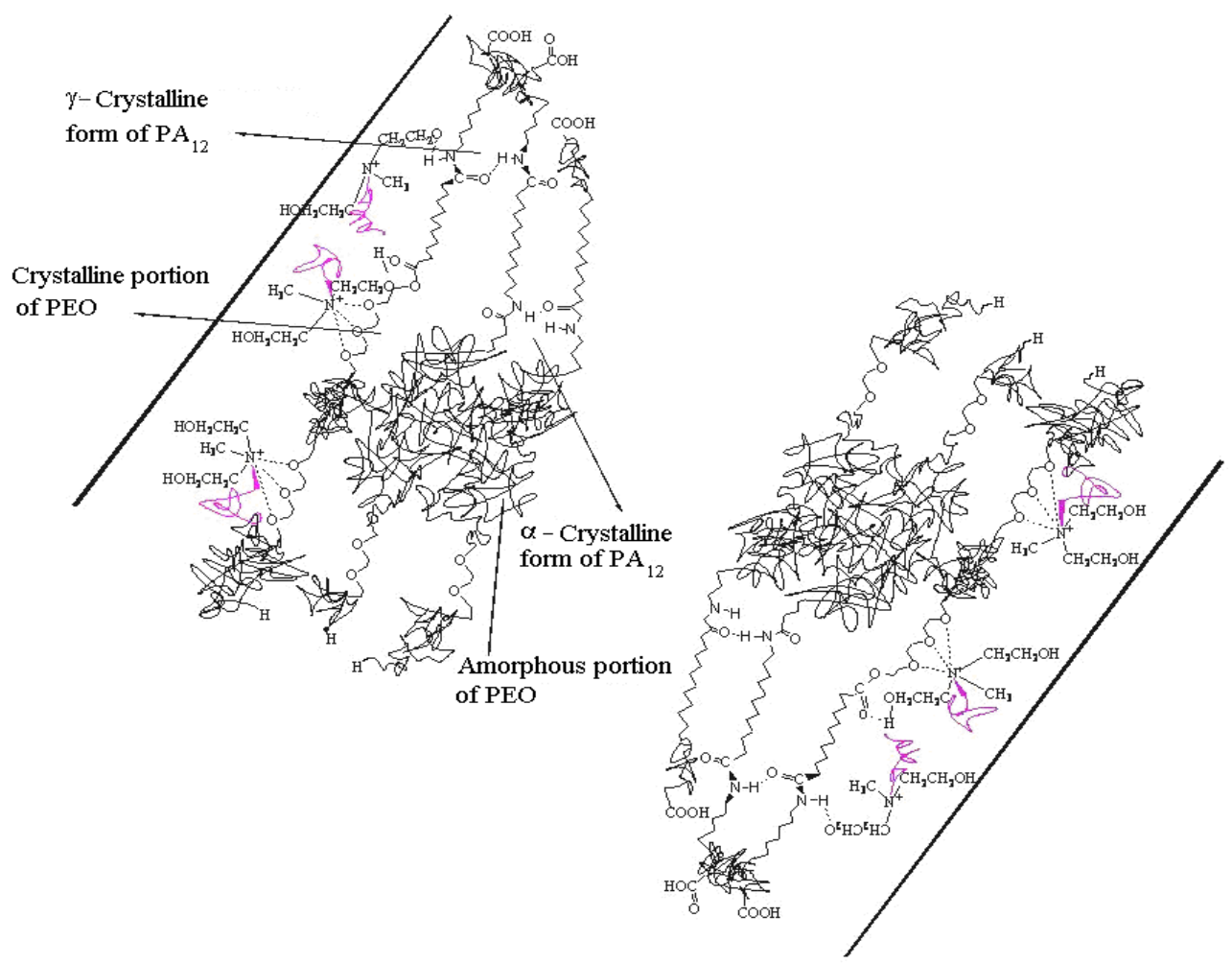

Fig. 9 b. Schematic drawing showing the exfoliation morphology in which the surface effect of montmorillonite becomes stronger.

The addition of $2.5 \mathrm{wt} . \%$ and $5 \mathrm{wt} \%$ organoclay led to the formation of exfoliation /intercalation PEBAX nanocomposites. As a consequence, the 2.5 wt.\% organoclay nanocomposite demonstrated different macroscopic results than the $5 \mathrm{wt} \%$ organoclay nanocomposite. This fact, as depicted schematically in Fig. 9a and b, implied that the dispersion extent of the silicate layers and the ratio of silicate sheets to tactiod played an important role in the organoclay nanocomposites.

In other words, a percolated clay network composed of layered OMMT will be constructed after threshold content of OMMT was reached [28]. So, OMMT sheets before the construction of a percolated filler network cause the observed macroscopic properties. This critical content of OMMT, where the percolated clay network begins to form, varies with the polarity of polymer chains. In addition, each of the blocks of copolymer can be affected by the presence of the clay surface, separately. The DSC and TGA results along with the mechanical behavior of the 5 wt.\% organoclay PEBAX exhibited that increasing the concentration of organic modifier groups with increasing the organoclay content which were squeezed out by the PEO blocks of PEBAX can affect the properties of nanocomposite, too. And this reduces the glass transition temperature, accelerates the rate of degradation of polymer chains and reduces the modulus.

\section{Experimental part}

\section{Materials}

The PEBAX ${ }^{\circledR}$, used in the present work, was purchased from the ATOFINA Chemical Co. and composed of polytethyleneoxide (PEO) and Nylon12, having the trade name of PEBAX MX1508. It contained heat, UV, oxidation stabilizer. The organoclay 
(OMMT), under the trade name of Cloisite 30B, was prepared by Southern Clay Co. (Gonzales, TX). The Cloisite 30B was organically modified sodium in MMT, with a quaternary ammonium salt (methyl-tallow-bis-2-hydroxy ethyl ammonium), demonstrating a cationic exchange capacity (CEC) of $90 \mathrm{meq} / 100 \mathrm{~g}$ clay. The particle size range of the nanoclay was $2-13 \mu \mathrm{m}$.

\section{Preparation}

Before processing, the aluminosilicate powders and the PEBAX ${ }^{\circledast}$ granules were dried for $8 \mathrm{~h}$ at $80^{\circ} \mathrm{C}$ in a vacuum oven.

The PEBAX ${ }^{\circledR}$ resins and the organoclay were extruded with a twin-screw extruder (ZSK 25, L/D $=40$ ) at a screw speed of $200 \mathrm{rpm}$. The temperature profile of the barrel was: $150,155,160,170,185$ and $195^{\circ} \mathrm{C}$. The organoclay content of the composites was kept at 0, 2.5 and 5 wt.\%, labeled as PEBA 0, PEBA 2.5 and PEBA 5, respectively. After melt mixing, the extruded blend was palletized, followed by ovendrying before further characterization.

The tensile specimens were prepared as sheets by compression molding under the temperature of $190^{\circ} \mathrm{C}$ and the pressure of 50 bar.

\section{Characterization}

The thermogravimetric analyses were performed with the aid of a TGA Q50 thermogravimetric analyzer from the TA instruments with a heating ramp of $20{ }^{\circ} \mathrm{C}$ $\mathrm{min}^{-1}$ under argon flow from room temperature to $700^{\circ} \mathrm{C}$.

The thermal behavior was measured with a DSC Q100 from the TA instruments with the heating and cooling ramp of $10^{\circ} \mathrm{C} \mathrm{min}{ }^{-1}$ from room temperature to $250{ }^{\circ} \mathrm{C}$ under argon flow. The size of each samples were $2-2.5 \mathrm{mg}$.

The Fourier transform infrared (FT-IR) analysis was performed on a Bruker Equinox55 Analyzer, equipped with a DTGS detector and a golden gate micro ATR from $600 \mathrm{~cm}^{-1}-3,500 \mathrm{~cm}^{-1}$.

A tensile testing machine was employed for the performance of the respective test (Cesare Galdabini S.P.A, Italy) at the cross head speed of $500 \mathrm{~mm} \mathrm{~min}^{-1}$. The width and thickness of the samples were kept as $5.5 \mathrm{~mm}$ and $3.9 \mathrm{~mm}$.

The melt flow index (MFI) was analyzed with the melt flow quick index (Ceast, Italy) with the load of $2160 \mathrm{~g}$. The X-ray diffraction (XRD) patterns of the samples were recorded by a SEIFERT diffractometer (XRD 3003 PTS). The scan range varied from $2 \theta=1$ to $2 \theta=10$.

Scanning electron microscopic images were taken with Zeiss CEM 902A (Oberkochen, Germany) and the images of TEM were obtained on a ZIESS-902A $\mathrm{TEM}$ at an accelerating voltage of $80 \mathrm{KV}$.

\section{Acknowledgements}

The authors gratefully acknowledge the kind assistance from Mrs. Fotuhi in the thermal analysis laboratory of the University College of Science in the University of Tehran for TGA and DSC analyses, Mr. Rahmani from the Baspar Nano Bon Company for useful collaborations. We thank Mr. Hashemi in the School of Geology, University College of Science, University of Tehran and Dr. Sh. Ahmadi from Institute 
of Biophysics and Biochemistry (IBB), University of Tehran for TEM, SEM analyses for helpful discussions.

\section{References}

[1] Kim, T. H.; Lim, S. T.; Lee, C. H.; Choi, H. J.; Jhon, M. S. J. Appl. Polym. Sci. 2003, 87, 2106.

[2] Fornes, T.D.; Yonn, P.J.; Keskkula, H.; Paul, D. R. Polym. 2001, 42, 9929.

[3] Bureau, M. N.; Denault, J.; Cole, K. C.; Enright, G.D. Polym. Eng. Sci. 2002, 42, 1897.

[4] Tjong, S. C. ; Xu, Y. Z. J. Appl. Polym. Sci. 2002, 86, 2337.

[5] Limary, R.; Green, P. F. in Polymer Nanocomposites: Synthesis, Characterization, Characterization, and Modeling, ACS. R. Krishnamoorti, R. A. Vaia. Ed., 2002, Symposium Series 804.

[6] Kojima, Y.; Usuki, A.; Okada, M.; Fukushima, Y.; Kurach, T.; Kmigaito, O. J Mater. Res. 1993, 8, 1185.

[7] Ke, Y.; Long, C.; Qi, Z. J. Appl. Polym. Sci. 1999, 71, 1139.

[8] Messersmith, P. B.; Giannelis, E. P. J. Polym. Sci. Part A: Polymer. Chem. 1995, 33, 1047.

[9] Akelah, A.; Moet, A. J. Mater. Sci. 1996, 31, 3589.

[10] Vaia, R. A.; Giannelis, E. P. Macromol. 1997, 30, 7990.

[11] Yoon, P. J.; Fornes, T.D.; Paul, D. R. Polym. 2002, 43, 6727.

[12] Hackatt, E.; Manias, E.; Giannelis, E. P. J. Chem. Phys. 1998, 108, 7410.

[13] Bharadwaj, R. K.; Vaia, R. A.; Farmer, B. L. in Polymer Nanocomposites: Synthesis, Charactrization, Charactrization, and Modeling, ACS. R. Krishnamoorti, R. A. Vaia. Ed., 2002, Symposium Series 804.

[14] Sridhar, S.; Surymurali, R.; Smitha, B.; Aminabhavi, T. M. Coll. Surf. A. Physiochem. Eng. Asp. 2007, 297, 267.

[15] Chen, J. C. Y. Thesis presented to the University of Waterloo, Ontari, Canada, 2002.

[16] Ratna, D.; Diveker, S.; Samui, A. B.; Chakraborty, B. C.; Banthia, A. K. Polym. 2006, 47, 4068.

[17] Aranda, P.; Mosqueda, Y.; Perez-Cappe, E.; Ruiz-Hitzky, E. J. Polym. Sci. Part B: Polym. Phys. 2003, 41, 3249.

[18] Hwu, J.M.; Jiang, G.J.; Gao, Z.M.; Xie, W.; Pan, W.P. J. Appl. Polym., Sci, 2002, 1702.

[19] Gilman, J.W. Appl. Clay Sci. 1999, 15, 31.

[20] Leszczynska, A.; Njuguna J.; Pielichowski, K.; Banerjee, J.R. Thermochemica acta. 2007, 453, 75.

[21] Qu, C. F. J. Appl. Polym. Sci. 2003, 89, 3315.

[22] Petrovic, X. S.; Javani, I.; Waddong, A.; Banhegyi, G. J. Appl. Polym. Sci. 1993, 3, 2063.

[23] Shah, R. K.; Paul, P.R. Polym. 2006, 47, 4075.

[24] Chiu, H. T.; Shong, Z J. J. App. Polym. Sci. 2006, 101, 3713.

[25] Ratna, D.; Direkar, S.; Patchaiappan, S.; Samui, A. B.; Chakraborty, B. C. J. Polym. Int. 2007, 56, 900.

[26] Barrera, M. A.; Vega, J. F.; Aguilar, M.; Salazer, J. M. J. Mat. Proc. Tech. 2006, $174,71$.

[27] Wang, K.; Liang, S.; Deng, J.; Yang, H.; Zhang, Q.; Fu, Q.; Dong, X.; Wang, D.; Han, C. C. Polym. 2006, 47, 7131.

[28] Wang, K.; Liang, S.; Du, R.; Fu, Q. J. Polym. Sci. part B : Polym. Phys. 2005, 43, 
2005.

[29] Zhou, H.; Zhang, S.; Yang, M. J. Appl. Polym. Sci. 2008, 108, 3822.

[30] Ray, V. V.; Banthia, A. K.; Schick, C. Polym. 2007, 48, 2404.

[31] Xu, Y.; Ren, X.; Hanna, M. A. J. Appl. Polym. Sci. 2006, 99, 1684.

[32] Loyens, W.; Maurer, F. H. J.; Jannasch, P. Polym. 2005, 46, 7334.

[33] Pantoustier, N. ; Lepoitievin, B. ; Alexander, M. ; Kubies, D. ; Calberg, C.; Jerome, R.; Dubois, P. J. Polymer. Eng. Sci. 2002, 42, 1928.

[34] Shen, Z.; Simon, G. P.; Cheng, Y. B. Polym. 2002, 43, 4251.

[35] Ruiz-Hitzky, E.; Aranda, P. Adv Mater. 1990, 2, 454.

[36] Aranda, P.; Ruiz-Hitzky, E. Chem Mater. 1992, 4, 1395. 